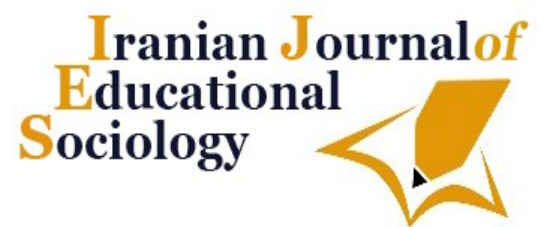

Iranian Journal of Educational Sociology

(Interdisciplinary Journal of Education)

Available online at: $\underline{\text { http://www.iase-idje.ir/ }}$

Volume 3, Number 3, October 2020

\title{
Investigate the Mediating Role of Attitudes to Cheating in the Relationship between Social Support and Educational Justice with Cheating Behavior
}

\author{
Fahimeh Babanejad ${ }^{1}$, Hassan Shams Esfandabad ${ }^{2 *, 3}$, Hooman Namvar ${ }^{3}$ \\ 1. PhD Student of Educational Psychology, Department of Psychology, Saveh Branch, Islamic Azad University, Saveh, \\ Iran. \\ 2. Associate Professor, Department of Psychology, Faculty of Social Sciences, Imam Khomeini International University, \\ Qazvin, Iran. \\ 3. Assistant Professor, Department of Psychology, Saveh Branch, Islamic Azad University, Saveh, Iran.
}

\section{Article type: \\ Research}

\section{Article history:}

Received date: 2020/06/16

Review date: 2020/08/03

Accepted date: 2020/08/9

\section{Keywords:}

Attitudes to cheating, social support, educational justice, cheating

behavior, students

\begin{abstract}
Purpose: This research aimed to investigate the mediating role of attitudes to cheating in the relationship between social support and educational justice with cheating behavior.

Methodology: Present study was cross-sectional from type of correlation. The research population was all high school female students of Tehran city in 2018-19 academic years with number of 120000 people. The sample size was calculated according to Cochran's formula 400 people who were selected by multi-stage cluster sampling method. The research instruments were the questionnaires of attitudes to cheating (Fealy \& et al, 2014), social support (Zimet \& et al, 1988), educational justice (Golparvar, 2011) and cheating behavior (Newsted \& et al, 1996). Data were analyzed by structural equation modeling method with using path analysis in Amos-23 software.

Findings: The findings showed that social support and educational justice had a negative and direct effect on attitudes to cheating and cheating behavior and attitudes to cheating had a positive and direct effect on cheating behavior. Also, social support and educational justice with mediating attitudes to cheating had a negative and indirect effect on cheating behavior $(\mathrm{P}<0.01)$. In addition, the model of mediating role of attitudes to cheating in the relationship between social support and educational justice with cheating behavior had a good fit.

Conclusion: Based on the results, to reduce cheating behavior can be developed and implemented through workshops programs to change in social support, educational justice and attitudes to cheating.
\end{abstract}

Please cite this article as: Babanejad F, Shams Esfandabad H, Shams Esfandabad H. (2020). Investigate the Mediating Role of Attitudes to Cheating in the Relationship between Social Support and Educational Justice with Cheating Behavior. Iranian Journal of Educational Sociology. 3(3): 88-96.

\footnotetext{
* Corresponding author: gangikamran@yahoo.com
} 


\section{Introduction}

Educational systems have long faced a pervasive phenomenon called fraud, and the rate of fraud has been steadily increasing over the past 30 years and has become so prevalent with the advancement of new technologies that it can be considered a pervasive problem in educational institutions (Alizadeh Sani \& et al, 2016). Fraud is an unrealistic display of one's knowledge or pretending to be literate and knowledgeable, using inappropriate methods. In other words, academic fraud is a set of behaviors based on deception and deception to achieve educational outcomes that one does not deserve (David, 2015). Cheating behavior is a psychological disease that increases effects such as feelings of fear, inferiority and secrecy in individuals (Pfattheicher \& et al, 2019). Some educators consider fraud to be a coercive behavior that is influenced by the environment, while others consider fraud to be due to internal or personality factors (Starovoytova \& Namango, 2016). People who engage in fraudulent behavior during their school years also commit fraud in their daily lives, jobs and careers (Topirceanu, 2017).

One of the factors influencing fraud behavior is social protection (Monteiro \& et al, 2018). Social support is conceptualized as a support network in the form of received and perceived support, which refers to the individual's mental assessment of the amount of support received by others (Ren \& Li, 2020). This structure is a combination of three elements of emotion (expressing love and affection), acknowledgment (awareness of appropriate behavior and feedback) and help (helping and assisting in doing things) (Demirci $\&$ et al, 2017). People with social support are more resilient to stressors that lead to reduced health and quality of life and seek help from others to address life challenges when necessary (Huang \& et al, 2019). Another factor influencing cheating behavior is educational justice (Alt, 2014). Educational justice means equal access to all educational facilities, regardless of field of study, ethnicity, gender, religion, culture, grade point average, ethics and behavior, dress code, and demographic and personality factors (Martin, 2020). This structure enables all learners in an environment to have equal opportunities and to provide equal opportunities for their talents to grow and flourish (Meyer, 2020). Educational justice and its perception in educational environments have many functions such as increasing the sense of worth, efficiency and self-esteem and reducing anxiety, stress and academic stress (Yamani \& et al, 2017). The most important principles of justice include proportionality between achievements and efforts and contributions, the degree of participation and participation in decisions related to oneself and others, having the right to respect, stability and non-discrimination, equal and non-partisan approaches and decisions, Being able to object to unequal, wrong and unjust conditions, expecting decisions based on community and accurate information, observing the conditions and needs of individuals and mastering the criteria and values in decisions and behaviors (Ben Shahar, 2017).

One of the variables that can mediate between social support and educational justice with cheating behavior is attitude to cheating, Attitude to cheating means that a person judges and evaluates the act of cheating negatively or positively, which shows that the person views cheating as a positive behavior or a negative behavior (Asokan \& et al, 2013). If students believe that others are more successful by cheating, their morale will improve and the feeling of injustice will increase among learners (Kayisoglu \& Temel, 2017). Attitudes toward cheating are associated with cheating behavior, and many learners consider cheating to be acceptable or a skill, which increases the acceptance of cheating among learners and decreases educational justice (Balik \& et al, 2010).

Few studies have examined the relationships between social support, educational justice, attitudes toward fraud, and fraud behavior. For example, the results of Sabzian et al. (2020) showed that academic ethics had a significant negative relationship with academic fraud. Sarikhani et al. (2019) while conducting a study concluded that the attitude towards fraud reporting and moral commitment had a positive and significant effect on the intention to report fraud. In another study, Monteiro et al. (2018) reported that social media experience was effective in reducing cheating behavior. Also, the results of Sabzian et al. (2018) showed a significant negative effect of favorable emotional and supportive family atmosphere on 
academic fraud. In another study, Sabzian et al. (2017) reported that academic ethics, favorable emotional and supportive family atmosphere, and educational justice had a significant negative relationship with academic fraud. Golparvar (2016) found that educational injustice had a significant positive relationship with academic fraud, but educational justice did not have a significant relationship with academic fraud. In addition, the results of Afrazandeh et al. (2016) showed that educational justice had a positive and significant relationship with civic-educational behaviors. Sadeghi et al. (2017) in a study concluded that the attitude of cheating is effective in increasing behavior and attempted cheating. In another study, Alt (2016) reported that there was a significant negative relationship between the experience of justice and attitudes toward academic fraud.

On the one hand, the rate of fraud is very high and increasing, and on the other hand, academic fraud causes a decline in real academic performance, and learners with academic fraud behavior will cheat more in their future careers. As a result, in order to reduce fraud, we must first identify the factors associated with it and then design and implement programs to reduce fraud based on them. One of the main gaps felt in previous studies is their lack of attention to the role of social support and educational justice on attitudes toward fraud and fraud behavior, and another important point is the difference in research results mentioned in the research background section. Therefore, this study aimed to investigate the mediating role of attitudes toward fraud in the relationship between social support and educational justice with fraud behavior.

\section{Methodology}

The present study was a cross-sectional correlational study. The study population was 120,000 female high school students in Tehran in the 2018-19 academic year. The sample size was estimated based on Cochran's formula of 383 people. In this study, to ensure the sample size, the sample size of 400 people was considered, which was selected by multi-stage cluster sampling. For this purpose, first four districts were selected randomly from different districts of Tehran and then two schools from each district and three classes from each school in different grades were selected and all the students of those classes were selected as a sample. The process of conducting the research was that after coordination with the education officials of Tehran, a list of districts and schools was prepared and then sampled from the districts and schools. Then the researcher referred to the sampled schools and after coordination with school officials for students to observe ethical points and the importance and necessity of the research were stated and they were asked to respond carefully to the following tools.

Attitude to Fraud Questionnaire: This questionnaire was designed by Fealy et al. (2014). This tool has 11 items that are scored from one to five points using a five-point Likert scale, and some items are scored inversely, and the tool score is calculated with the total score of the items, so the range of scores between 11-55 and higher indicates a more positive attitude to It is fraud. Fealy et al. (2014) confirmed the content validity of the instrument with the opinion of experts and reported its reliability by Cronbach's alpha method of 0.89 . In the present study, the reliability value was 0.76 by Cronbach's alpha method.

Social Support Questionnaire: This questionnaire was designed by Zimet et al. (1988). This tool has 12 items that are scored from one to five using the five-point Likert scale, and the tool score is calculated with the total score of the items, so the range of scores between 12-60 and higher indicates more social support. Zimet et al. (1988) confirmed the validity of the instrument construct by exploratory factor analysis and its reliability by Cronbach's alpha method of 0.92. In Iran, Barmaki et al. (2020) reported the reliability of the instrument by Cronbach's alpha method of 0.90 . In the present study, the reliability value was 0.83 by Cronbach's alpha method.

Educational Justice Questionnaire: This questionnaire was designed by Golparvar (2011). This tool has 14 items that are scored from one to seven using the Likert scale of seven points and the tool score is calculated with the total score of the items, so the range of scores between 14-198 and higher score 
indicates more educational justice. Golparvar (2011) reported divergent validity of the instrument with educational injustice of -0.48 which was significant at the level of less than 0.01 and its reliability by Cronbach's alpha method of 0.86 . In the present study, the reliability value was 0.89 by Cronbach's alpha method.

Fraud Behavior Questionnaire: This questionnaire was designed by Newstead et al. (1996). The tool has 21 items that are scored from one to five using a five-point Likert scale, and the tool score is calculated with the total score of the items, so the range of scores between 105-21 and higher indicates more cheating behavior. Newstead et al. (1996) confirmed the content validity of the instrument and reported its reliability by Cronbach's alpha method of 0.95. This tool has never been used in Iran and in the present study, the face and content validity of the tool was confirmed by experts and the reliability was obtained by Cronbach's alpha method of 0.92 .

Data were collected by analyzing the above questionnaires by structural equation modeling using path analysis in Amos-23 software.

\section{Findings}

In this study, 400 female high school students were present, whose frequency and percentage of demographic information, including educational level and age, are reported in Table 1.

Table1. Frequency and frequency of demographic information of female students

\begin{tabular}{|c|c|c|c|}
\hline Variables & Levels & Abundance & Frequency \\
\hline \multirow{3}{*}{ Grade } & tenth & 137 & $34 / 25 \%$ \\
\hline & Eleventh & 131 & $32 / 75 \%$ \\
\hline & twelfth & 132 & $33 \%$ \\
\hline \multirow{3}{*}{ Age } & 16 years & 137 & $34 / 25 \%$ \\
\hline & 17 years & 131 & $32 / 75 \%$ \\
\hline & 18 years & 132 & $33 \%$ \\
\hline
\end{tabular}

According to the results of Table 1, most of the female students are in the tenth grade and are 16 years old (137 people, equivalent to 34.25\%). Mean standard deviation and correlation coefficients of social support, educational justice, attitude towards fraud and cheating behavior of female students are reported in Table 2.

Table2. Mean standard deviation and correlation coefficients of social support, educational justice, attitude to cheating and cheating behavior of female students

\begin{tabular}{cccccc}
\hline Variables & Average & The standard deviation & 1 & 2 & 3 \\
\hline 1. Social support & $44 / 15$ & $12 / 34$ & 1 & & \\
\hline 2. Educational justice & $74 / 54$ & $19 / 14$ & $0 / 21^{* *}$ & 1 & $-0 / 34^{* *}$ \\
\hline 3. Attitude to cheating & $41 / 87$ & $7 / 05$ & $-0 / 47^{* *}$ & 1 & $-0 / 35^{* *}$ \\
\hline 4. Cheating behavior & $83 / 23$ & $16 / 91$ & $-0 / 41^{* *}$ & 1 \\
\hline
\end{tabular}

According to the results of Table 2, social support and educational justice have a significant negative relationship with attitudes toward fraud and cheating behavior, social support has a significant positive relationship with educational justice and attitudes toward fraud have a significant positive relationship with cheating behavior $(\mathrm{P}<0.01)$. Therefore, there is an assumption of sufficient correlation between research variables to perform path analysis. Also, the assumption of normality based on skew and elongation values was confirmed due to the fact that all values are in the range of +1 to -1 . Therefore, path analysis method can be used in the analyzes Fit indicators of the model of the mediating role of attitudes toward fraud in the relationship between social support and educational justice with the cheating behavior of female students were presented in Table 3. 
Table3. Fit indicators of the model of mediating the attitude of cheating in the relationship between social support and educational justice with cheating behavior of female students

\begin{tabular}{ccccccc}
\hline Indicators & $\chi 2 / \mathrm{df}$ & RMSEA & CFI & NFI & GFI & AGFI \\
\hline Statistics & $1 / 98$ & $0 / 07$ & $0 / 94$ & $0 / 91$ & $0 / 93$ & $0 / 95$ \\
\hline Acceptance limit & Less than 3 & Less than 0.1 & Above 0.9 & Above 0.9 & Above 0.9 & Above 0.9 \\
\hline
\end{tabular}

Based on the results of Table 3, the model mediates the attitude of cheating in the relationship between social support and educational justice with the cheating behavior of female students. The fitted model with standard path coefficients is reported in Figure 1 and the results of the research hypotheses are reported in Table 4.

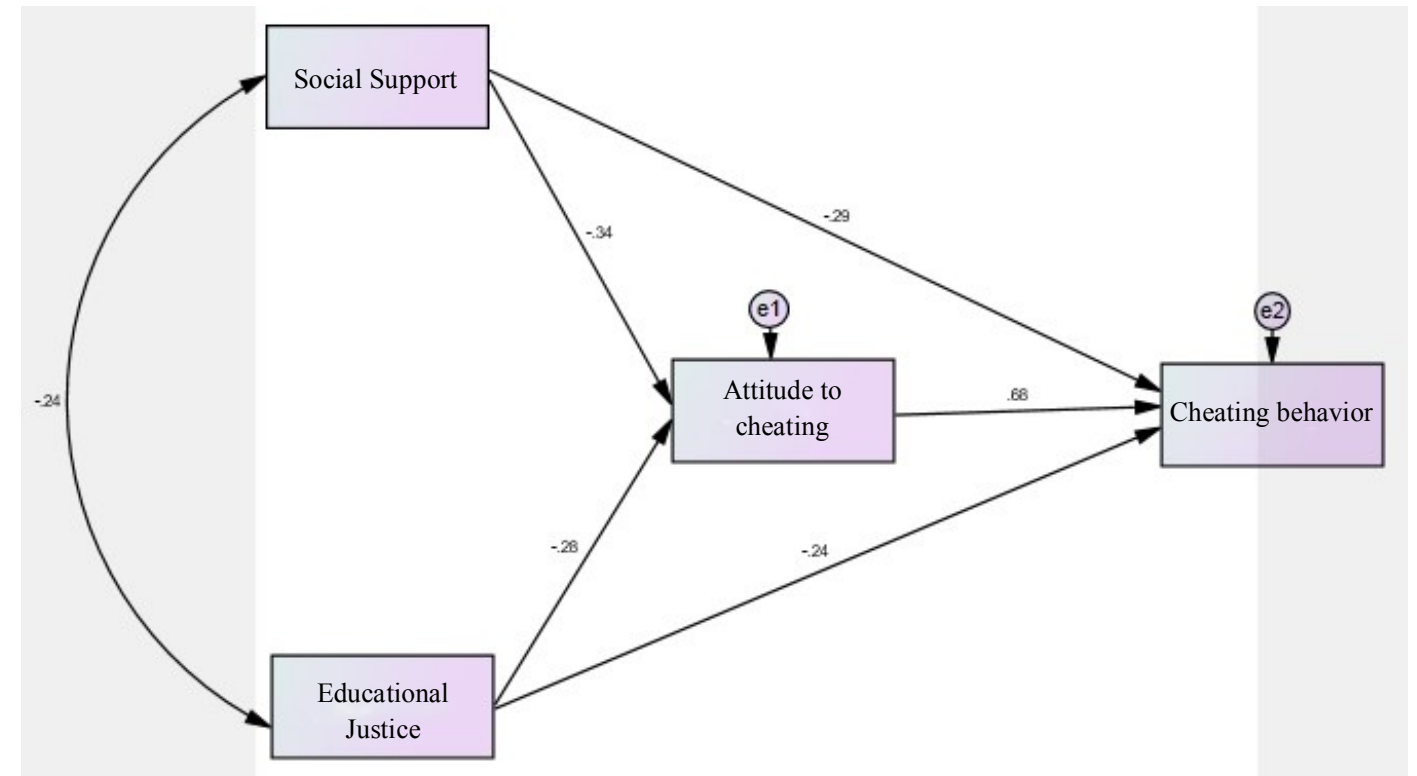

Figure1. Fit model of the mediating role of attitudes toward cheating in the relationship between social support and educational justice with cheating behavior of female students with standard coefficients of paths

Table4. Results of research hypotheses in female students

\begin{tabular}{lccc}
\hline \multicolumn{1}{c}{ Research hypotheses } & $\begin{array}{c}\text { Standard } \\
\text { coefficient }\end{array}$ & $\begin{array}{c}\text { Amara } \\
\mathrm{t}\end{array}$ & meaningful \\
\hline 1. Social support has a significant direct effect on attitudes toward fraud. & $-0 / 34$ & $-4 / 17$ & $\mathrm{P}<0 / 01$ \\
\hline 2. Social support has a significant direct effect on cheating behavior. & $-0 / 29$ & $-3 / 42$ & $\mathrm{P}<0 / 01$ \\
\hline 3. Educational justice has a significant direct effect on attitudes toward fraud. & $-0 / 28$ & $-3 / 59$ & $\mathrm{P}<0 / 01$ \\
\hline 4. Educational justice has a significant direct effect on cheating behavior. & $-0 / 24$ & $-3 / 21$ & $\mathrm{P}<0 / 01$ \\
\hline 5. Attitude to cheating has a direct effect on cheating behavior. & $0 / 68$ & $5 / 38$ & $\mathrm{P}<0 / 01$ \\
\hline $\begin{array}{l}\text { 6. Social support through attitudes toward fraud has a significant indirect effect on } \\
\text { fraud behavior. }\end{array}$ & $-0 / 23$ & $-2 / 93$ & $\mathrm{P}<0 / 01$ \\
\hline $\begin{array}{l}\text { 7. Educational justice has a significant indirect effect on cheating behavior through } \\
\text { the attitude of cheating. }\end{array}$ & $-0 / 19$ & $-2 / 35$ & $\mathrm{P}<0 / 01$ \\
\hline
\end{tabular}

According to the results of Table 4, social support and educational justice have a direct and negative effect on attitudes toward fraud and fraud behavior and attitudes toward fraud have a direct and positive effect on fraud behavior. Also, social support and educational justice have an indirect and negative effect on cheating behavior through the attitude of cheating $(\mathrm{P}<0.01)$.

\section{Discussion}

Academic cheating has a high and increasing rate and such people cheat in their future jobs, therefore, this study was conducted to investigate the mediating role of attitudes toward cheating in the relationship between social support and educational justice with cheating behavior. 
The findings showed that social support had a direct and negative effect on the attitude towards fraud and fraud behavior, which was in line with the findings of Monteiro et al. (2018), Sabzian et al. (2018) and Sabzian et al. (2017). Explaining the significant negative effect of social support on attitudes toward cheating and cheating behavior of female students based on the research of Monteiro et al. (2018), it can be said that having a social network makes a person realize that he is loved, cared for, valued and Respected and belongs to a network of communications. The more these communication and support networks are, the more it helps people cope with environmental pressures and puts people in more relaxing psychological situations, which increases the health and quality of life of people, and such people are usually happier in life. , Have a more optimistic view of academic and non-academic life. As a result, it can be expected that increasing social support or social networking through the above processes and by improving the normative behaviors of students in students will reduce their attitudes toward cheating and cheating behavior.

Other findings showed that educational justice had a direct and negative effect on the attitude towards fraud and fraud behavior, which is in line with the findings of Sabzian et al. (2020), Sarikhani et al. (2019), Sabzian et al. (2017), Afrazandeh et al. 2016) and Alt (2016) were consistent with the findings of Golparvar (2016). Contrary to the findings of the present study, Golparvar (2016) concluded that educational justice had no significant relationship with academic fraud. In explaining this discrepancy based on the research of Sabzian et al. (2017) we can point to different ways of measuring cheating behavior and since in this study the basis of cheating is students' responses to the items of cheating behavior tools and not the practical situation, this possibility Social optimism error has affected the results and another possible reason is that the relationship between these two variables may be due to other variables such as personality traits, academic stress and self-efficacy, etc. that were not examined. Explaining the significant negative effect of educational justice on the attitude towards cheating and cheating behavior of female students based on the research of Afrazandeh et al. (2016) it can be said that based on the social exchange approach and the principle of retaliation when teachers in schools interact with students in justice Through a sense of selfworth, they increase students' capacity to help each other and to participate and adhere to rules. Justice in educational environments is associated with a sense of worth, and all students in these environments expect to enjoy the same services and facilities, while injustice creates feelings of doubt and anxiety and reduces the tendency to adaptive behaviors. It becomes students. Therefore, it is logical that increasing educational justice reduces the attitude and behavior of cheating and increasing educational injustice increases them among female students. Another explanation based on Alt (2016) research is that justice has long been one of the most important issues and concerns of thinkers in various sciences and justice continues the life and survival of social systems and integrates social elements together, while injustice causes their separation. Provides. Thus, educational justice can increase appropriate academic behaviors and reduce inappropriate academic behaviors, including attitudes toward cheating and cheating behavior.

Also, the findings showed that the attitude to cheating had a direct and positive effect on cheating behavior, which was in line with the findings of Sarikhani et al. (2019) and Sadeghi et al. (2017). Explaining the significant positive effect of the attitude of cheating on the cheating behavior of female students based on the research of Bakhtiyari Khoee \& Soleimani (2019), it can be said that the rising trend of documentarism in Iran has caused many problems and some people want a degree in the shortest possible time. Achieve their goals, this situation has brought with it many problems, and fraud and attitude towards it is one of these problems. Students at all levels take action to improve their grades, and fraud is a serious issue that not only affects the quality of the education system, but also spreads injustice to non-fraudsters. Since the attitude towards cheating shows the learners' assessment of the negative or positive behavior of cheating, so it is logical that by increasing the attitude to cheating, the rate of cheating behavior increases in all students, including female students.

In addition, the findings showed that social support and educational justice had an indirect and negative effect on cheating behavior through the attitude of cheating. No research has been found in this field, but in 
explaining these findings, it can be said that the effect of social support and educational justice on cheating behavior is mediated by cognitive and motivational mechanisms. One of the most important cognitive mechanisms affecting cheating behavior is awareness of needs, cognitions and emotions. And the belief in success in any way and one of the most important motivational mechanisms affecting cheating behavior can be a positive view of cheating, low anxiety, lack of fear of success, motivation to progress and enthusiasm to study and continue. Since the attitude towards cheating means judging and evaluating the person from the negative or positive of the act of cheating, it shows that the person sees cheating as a positive behavior or a negative behavior. Thus, the attitude towards fraud has both cognitive and motivational dimensions. Therefore, given that social support and educational justice had a direct and negative effect on attitudes toward cheating and attitudes toward cheating had a direct and positive effect on cheating behavior, it makes sense when the effect of social support and educational justice on cheating behavior was mediated by attitudes toward Investigate fraud, attitudes to fraud play an effective role between social support and educational justice with fraud behavior. As a result, attitudes toward cheating can be a good mediator between social support and educational justice with cheating behavior, and social support and educational justice through attitudes toward cheating modify cheating behavior in female students.

The most important limitations of the present study include the limitation of the research community to high school students in Tehran, the use of self-report tools such as a questionnaire to collect data, homosexuality of the research sample (female students) and inability to control some intervention variables including motivation and interest of some participants. And the motivation and interest of others were low. Based on the limitations, it is recommended that this research be performed on students of other grades, other cities and even boys and its results be compared with the results of the present study. Another recommendation is to use structured interviews to collect data. Based on the results of the present study, it is recommended to increase social support and educational justice to reduce cheating behavior and reduce the positive attitude towards cheating. For this purpose, use training workshops to increase social support and reduce attitudes toward cheating and use of professors And a fair and just teaching staff is essential for educational justice. 


\section{References}

Afrazandeh SS, Mirzaei T, Pouraboli B, Sabzevari S. (2016). Educational justice and educational citizenship behavior from perspective of nursing students. Journal of Medical Ethics. 10(35): 117-140.

Alizadeh Sani M, Nejat S, Shahi M, Arab M. (2016). The impact of spiritual intelligence on cheating: Neutralization as moderator. Iranian Journal of Culture in the Islamic University. 6(19): 293-308.

Alt D. (2014). Assessing the connection between students' justice experience and attitudes toward academic cheating in higher education new learning environments. Journal of Academic Ethics. 12(2): 113-127.

Asokan S, John JB, Janani D, Jessy P, et all. (2013). Attitudes of students and teachers on cheating behaviors: descriptive cross-sectional study at six dental colleges in India. Journal of Dental Education. 77(10): 1379-1383.

Bakhtiyari Khoee N, Soleimani E. (2019). Structural equation modeling of the relationship between goal orientation and attitudes toward cheating: Academic motivation as a mediating variable. Instruction and Evaluation Quarterly Journal. 12(46): 47-63.

Balik C, Sharon D, Kelishek S, Tabak N. (2010). Attitudes towards academic cheating during nursing studies. Medicine and Law. 29(4): 547-563.

Barmaki H, Parsa Moein K, Kalantari M. (2020). Providing model of job engagement based on personality characteristics with mediating social and organizational supports in schools of Tehran city. Journal of Social Psychology. 7(53): 13-23.

Ben Shahar TH. (2017). Educational justice and big data. Theory and Research in Education. 15(3): 306-320.

David LT. (2015). Academic cheating in college students: Relations among personal values, self-esteem and mastery. Procedia - Social and Behavioral Sciences. 18: 88-92.

Demirci K, Demirci S, Taskiran E, Kutluhan S. (2017). The effects of temperament and character traits on perceived social support and quality of life in patients with epilepsy. Epilepsy \& Behavior. 74: 22-26.

Fealy S, SafarPour S, RasouliAzar S. (2014). Effective factors on students' cheating behaviors on exams: A case study of Gorgan Islamic Azad University. Quarterly Journal of Research and Planning in Higher Education. 20(1): 5777.

Golparvar M. (2011). The role of academic ethics, educational justice and injustice among university student's education/citizenship behaviors. Journal of Modern Thoughts in Education. 5(4): 25-41.

Golparvar M. (2016). The role of educational ethics in relation between educational justice and injustice with educational cheating: Structural equation modeling. Educational Psychology. 11(37): 51-67.

Huang J, Wang X, Li W, An Y. (2019). The relationship between conscientiousness and posttraumatic stress disorder among young Chinese firefighters: The mediating effect of perceived social support. Psychiatry Research. 273: 450-455.

Kayisoglu NB, Temel C. (2017). An examination of attitudes towards cheating in exams by physical education and sports high school students. Universal Journal of Educational Research. 5(8): 1396-1402.

Martin C. (2020). Educational justice and the value of knowledge. Journal of Philosophy of Education. 54(1): 164182.

Meyer K. (2020). Talents, abilities and educational justice. Educational Philosophy and Theory, 5: 1-11.

Monteiro J, Silva-Pereira F, Severo M. (2018). Investigating the existence of social networks in cheating behaviors in medical students. BMC Medical Education. 18(1): 1-8.

Newstead SE, Franklyn-Stokes A, Armstead P. (1996). Individual differences in student cheating. Journal of Educational Psychology. 88(2): 229-241.

Pfattheicher S, Schindler S, Nockur L. (2019). On the impact of Honesty-Humility and a cue of being watched on cheating behavior. Journal of Economic Psychology. 71, 159-174.

Ren Y, Li M. (2020). Influence of physical exercise on social anxiety of left-behind children in rural areas in China: The mediator and moderator role of perceived social support. Journal of Affective Disorders. 266: 223-229.

Sabzian S, Ghadampour E, Mirderikvand F. (2018). Presenting a causal model of academic engagement and academic ethics with academic cheating: The mediating role of academic self-efficacy. Journal of School Psychology. 8(4): 131-155.

Sabzian S, Ghadampour E, Mirderikvand F. (2018). The causal model of academic cheating based on individual and contextual factors with the mediating role of academic self-efficacy. Quarterly Journal of Research in School and Virtual Learning. 5(3): 43-66. 
Sabzian S, Ghadampour E, Mirderikvand F. (2018). Providing a causal model for perceptions of emotional climate and flexibility of family with academic dishonesty: The mediating role of academic self-efficacy. Quarterly Journal of Social Work. 7(3): 32-43.

Sadeghi A, Ofoghi N, Banapour-Hammidy MH, Emami F. (2017). The survey of factors related to cheating among students of higher educational institutions city of Rasht. Strategic Research on Social Problems in Iran. 6(4): 35 52 .

Sarikhani M, Izadinia N, Daei-Karimzadeh S. (2019). Investigating the factors affecting the whistle-blowing intentions using the fraud triangle and the theory of planned behavior: An accountant's perspective. Iranian Journal of Value \& Behavioral Accounting. 3(6): 105-135.

Starovoytova D, Namango S. (2016). Factors affecting cheating-Behavior at undergraduate-engineering. Journal of Education and Practice. 7(31): 66-82.

Topirceanu A. (2017). Breaking up friendships in exams: A case study for minimizing student cheating in higher education using social network analysis. Computers \& Education, 115: 171-187.

Yamani N, Shaterjalali M, Eghbali B. (2017). Educational justice from the perspective of postgraduate students in a medical school in Iran: A qualitative study. Research and Development in Medical Education. 6(1): 23-28.

Zimet GD, Dahlem NW, Zimet SG, Farley GK. (1988). The multidimensional scale of perceived social support. Journal of Personality Assessment. 52(1): 30-41. 